\title{
Expression of immature and mature retinal cell markers in retinoblastoma
}

\begin{abstract}
Aim To clarify the expression of immature and mature retinal cell makers in retinoblastoma cells and to give insights into the cell origin of the retinoblastoma. Materials and methods Five samples from five eyes diagnosed with retinoblastomas were analysed by a standard immunohistochemistry using antibodies against Nestin and the hairy and enhancer of split mammalian homologue-1 (HES-1), both as markers for undifferentiated cells, and against Chx10, as a marker for both undifferentiated retinal cells and mature bipolar cells.

Photoreceptor-specific nuclear receptor (PNR) was used as a postmitotic rod photoreceptor cell-specific marker, glial fibrillary acidic protein (GFAP) as a mature glia cell marker, and microtubule-associated protein (MAP) 2 as a mature neuronal cell marker.

Results Nestin was detected in what were possibly Müller cells, but not in the tumour stroma. HES-1 was not detected in the retinoblastoma tissue. Chx10 was detected in one of the five samples. In this one sample, Chx10 expression was confined in a minor portion of the retinoblastoma cells. PNR was not detected in the retinoblastoma tissue. Expression of GFAP was detected only in the stromal cells of the tumour, which presumably represents reactive stromal astrocytes. In contrast, in all the samples, MAP2 was expressed in most of the retinoblastoma cells. Conclusions The results of the current study support that retinoblastomas are derived from mature neural cells but do not originate from tumour stem cell(s).
\end{abstract}

Eye (2008) 22, 678-683; doi:10.1038/sj.eye.6702715; published online 2 February 2007

Received: 30 June 2006 Accepted in revised form: 30 November 2006 Published online: 2 February 2007
Keywords: retinoblastoma; cell origin; immunohistochemical analysis
R Sakata and Y Yanagi

\section{Introduction}

A retinoblastoma is a most frequently encountered ophthalmic tumour in childhood. Despite numerous pathological studies, the origins of retinoblastomas are still controversial. ${ }^{1}$ Virchow advocated that retinoblastomas arise from the glial cells of the retina. Some investigators have suggested a neuronal cell as an origin of retinoblastomas. ${ }^{2-6}$ Using RB or RB/p107 knockout mice, a previous study demonstrated that cell-of-origin in retinoblastoma is naturally death-resistant inner nuclear layer precursor cells. ${ }^{7}$ It has also been suggested that primitive neuroectodermal cells with their potential for both neural and glial cell lineage are the cell origin of retinoblastomas. ${ }^{8-12}$ Additionally, when cells from retinoblastoma cultures were investigated with a scanning electron microscope, glial, and neuronal cells were observed, suggesting the cell origin of the retinoblastoma is a multipotential retinal stem cell. ${ }^{11}$ More recent study demonstrated that retinoblastoma cells were positively stained with cancer stem cell surface markers such as ABCG2 and MCM2, supporting that retinoblastoma is derived from stem cells. ${ }^{12}$ Other investigators have suggested that the retinoblastoma cells have the same origin as the photoreceptor cells. ${ }^{13-16}$

In contrast to the controversy over the cell origin of retinoblastomas, it has become generally accepted that several types of cancers of the central nervous system arise from the tumour stem cells, ${ }^{17}$ which are derived from the transformation of the neural stem cells, and are thought to have self-replication ability and differentiation potency. For example, in the gliosarcoma, the positive immunostaining of Nestin, an intermediate filament protein expressed in stem cells, ${ }^{18}$ supports that it contains undifferentiated cells. ${ }^{19}$ Other experimental studies have demonstrated that 
brain tumours contain cells possessing similar properties to neural stem cells, with the ability to self-renew. They also have potency for neuronal cells and glia cells, supporting the multipotential stem cell origin theory in the development of astrocytomas, gliocytomas, medulloblastomas, primitive neuroectodermal tumours, and ependymomas. ${ }^{20,21}$ Similar to the neurons in the central nervous system, it is generally considered that multipotential retinal stem cells give rise to all seven retinal cell types, that is, rod and cone photoreceptor cells, bipolar cells, horizontal cells, amacrine cells, Müller cells, and retinal ganglion cells, in the retinal developmental stage. ${ }^{22}$ However, it has not been clarified whether retinoblastomas, like several types of tumours in the central nervous system, originate from such retinal stem cells.

Recent studies have disclosed that several molecules are expressed at specific times during retinal differentiation, suggesting that such molecules can be utilized as markers to specify the cell types and the degree of differentiation. Several molecules are expressed at higher levels in immature retinal stem cells compared to mature retinal cells. For example, the expression of Nestin decreases upon differentiation. ${ }^{23} \mathrm{Chx} 10$, a transcriptional factor regulating retinal progenitor proliferation and bipolar cell differentiation, ${ }^{24}$ is expressed in immature retinal cells during retinal development, but in adulthood, it is exclusively expressed in the retinal bipolar cells. ${ }^{25}$ Additionally, the strong expression of HES-1, a basic helix-loop-helix transcriptional factor regulating neural development, ${ }^{26}$ is observed in immature retinal cells and its expression gradually decreases upon retinal maturation. ${ }^{27}$ On the other hand, several markers are expressed after the retinal cells are terminally differentiated. Photoreceptorspecific nuclear receptor (PNR) is expressed in retinal cells that are postmitotic and committed to photoreceptor cells. ${ }^{28}$ Microtubule-associated protein 2 (MAP2) antigen and glial fibrillary acidic protein (GFAP) antigen are generally considered to be expressed in mature neurons and glial cells, respectively, and not in immature cells. ${ }^{23}$

In this study, to clarify which factors are expressed in retinoblastoma cells and to give insights into the cell origin of retinoblastomas, we investigated the expression of the aforementioned immature and mature retinal cell markers in retinoblastoma specimens.

\section{Materials and methods}

\section{Samples}

Five samples from five eyes diagnosed with retinoblastoma were used (Table 1). They all derive from primary enucleation. Three were of the differentiated type, and the other two were undifferentiated, as classified by a haematoxylin and eosin stain of the

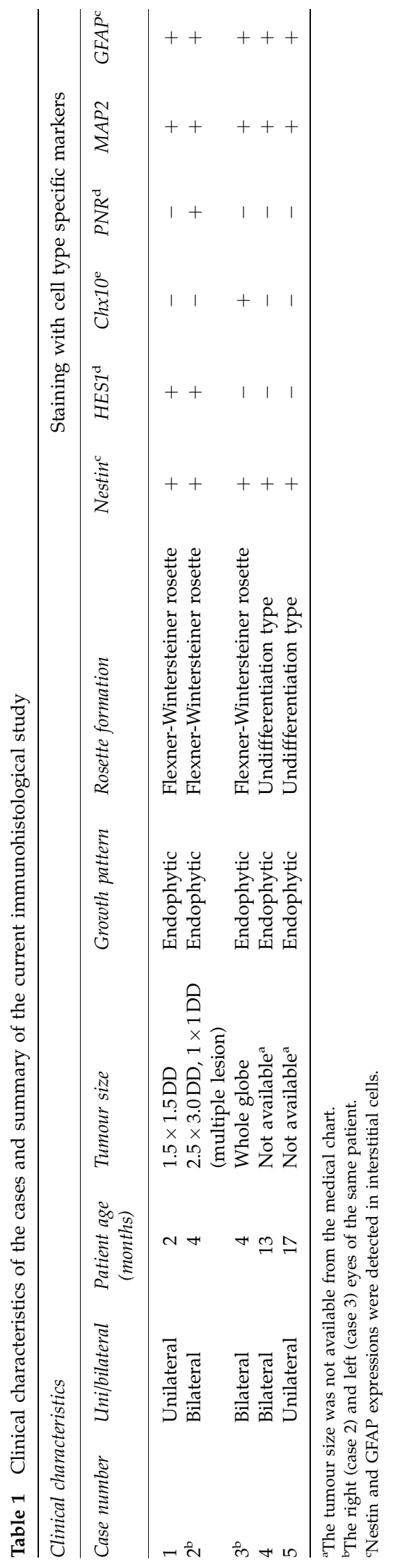



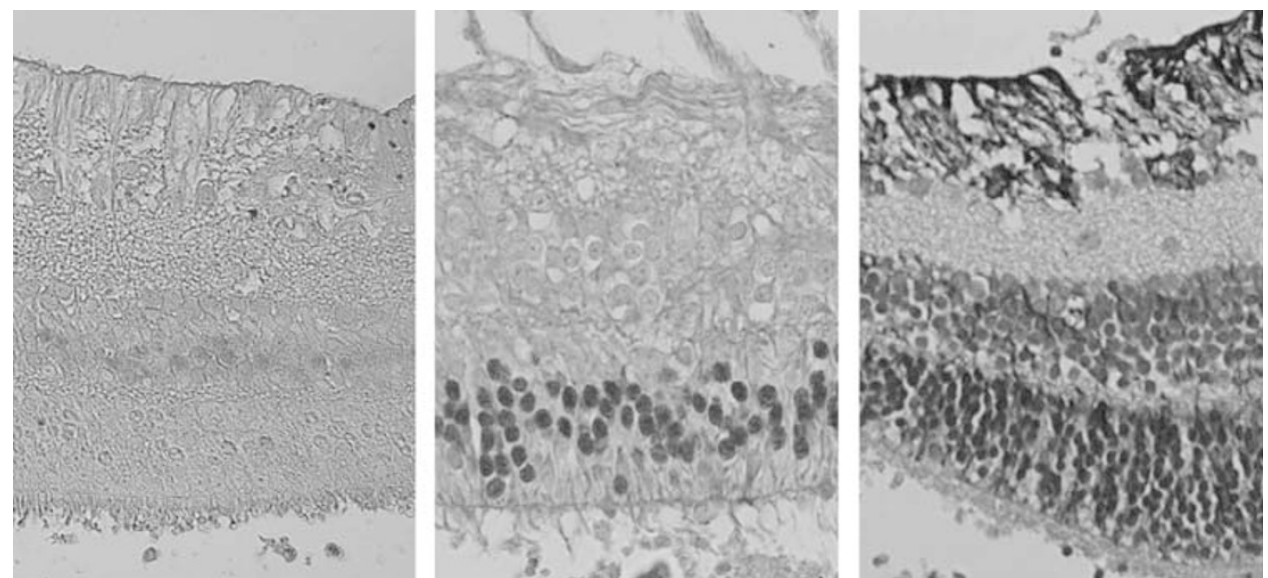

Figure 1 Representative immunohistochemical staining of the layered retina in the sample for Chx10 (left), PNR (middle), and GFAP (right). Original magnification $\times 400$.

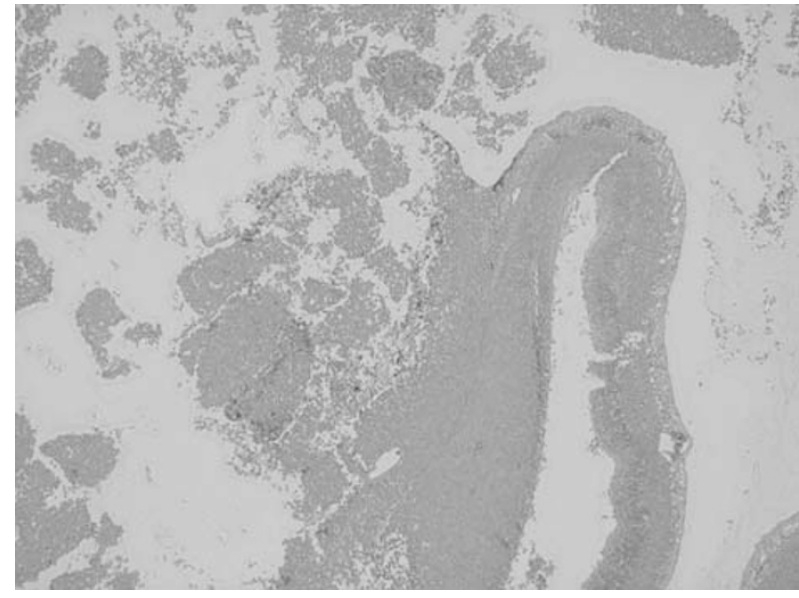

Figure 2 Representative immunohistochemical staining for Nestin. Nestin expression was detected not in the structure of retinoblastomas but in the stromal cells. Original magnification $\times 200$.

sections. The ages of the patients ranged from 2 to 17 months old.

\section{Immunohistochemistry}

Enucleated eyes were fixed in $4 \%$ paraformaldehyde, treated with ethanol and processed for paraffin embedding. Once embedded, 4.0- $\mu$ m sections of tissue were prepared for immunostaining. For immunohistochemistry, slides were deparaffinized and incubated in blocking solution (phosphate-buffered saline containing $0.1 \%$ bovine serum albumin and $2 \%$ calf serum) for $30 \mathrm{~min}$, followed by a primary antibody in the blocking solution. A standard immunoperoxidase procedure was performed using

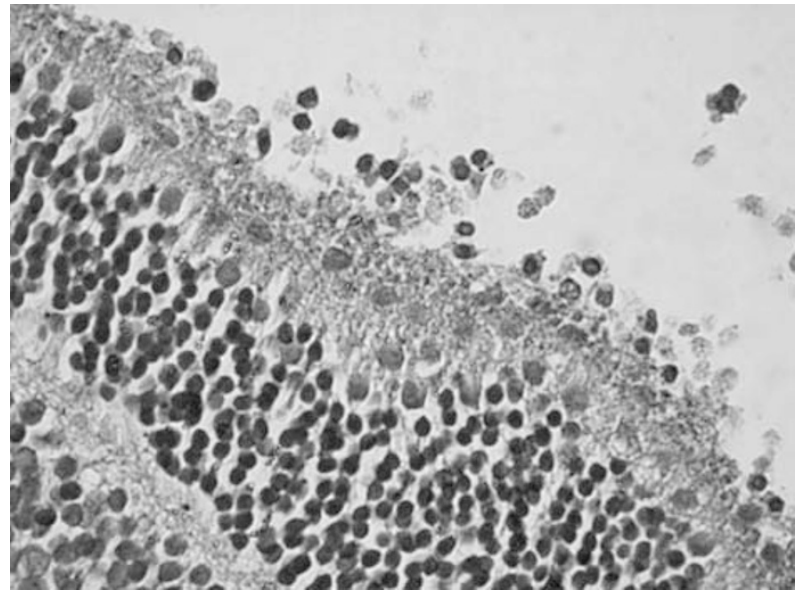

Figure 3 Representative immunohistochemical staining for HES-1. HES-1 expression was detected not in the structure of retinoblastomas but in the outermost part of the outer nuclear layer in normal retinas. Original magnification $\times 200$.

a kit (Vecter ABC kit, Vector), and Novared (Vector), which reacts with peroxidase to give a red reaction product, was used as the substrate. The primary antibodies were: Nestin and mammalian homologue of hairy and enhancer of split (HES)-1, both as the markers for undifferentiated cells, Chx10, as a marker for both undifferentiated retinal cells and for bipolar cells, PNR as a postmitotic rod photoreceptor cell specific marker, GFAP as a mature glia cell marker, and MAP2 as a mature neuronal cell marker. The samples were counterstained with haematoxylin where necessary. As negative controls, samples were reacted with normal rabbit serum or IgG controls, which gave no positive signals. 


\section{Results}

To identify the factors expressed in retinoblastomas, stage-specific markers were tested by immunohistochemical analysis. Several sections contained normal layered retinal structure adjacent to the retinoblastoma tissue, and served as controls for the antibodies including Chx10, PNR, and GFAP, which are expressed in bipolar cells, rod photoreceptor cells, and Müller cells, respectively (Figure 1a-c).

As a first step, the group of markers expressed in immature retinal cells, that is, Nestin, HES-1, and Chx10, were examined. In all the samples, patchy Nestin expressions were detected. The number of cells expressing Nestin was very low and the expression was detected not in the structure of the retinoblastomas but in the stromal cells, possibly representing Müller cells infiltrating into the retinoblastoma tissue (Figure 2). HES-1 was not detected in the retinoblastoma tissue. It was expressed only in the outermost part of the outer nuclear layer in the normal retinas (Figure 3). Chx10 was detected in one of the five samples. In this one sample, the expression was confined in a minor portion of the cells (Figure 4). In normal retina, Chx10 expression was detected in the inner nuclear layer, as expected (Figure 1a). Taking these results together, it can be said that there was little or no expression of immature retinal cell markers in the retinoblastoma tissue.

As a committed photoreceptor cell marker, expression of PNR was examined. As expected, PNR was expressed in the outer nuclear layer of the normal retinas (Figure 1b). However, in the retinoblastoma tissue, its expression was not detected.

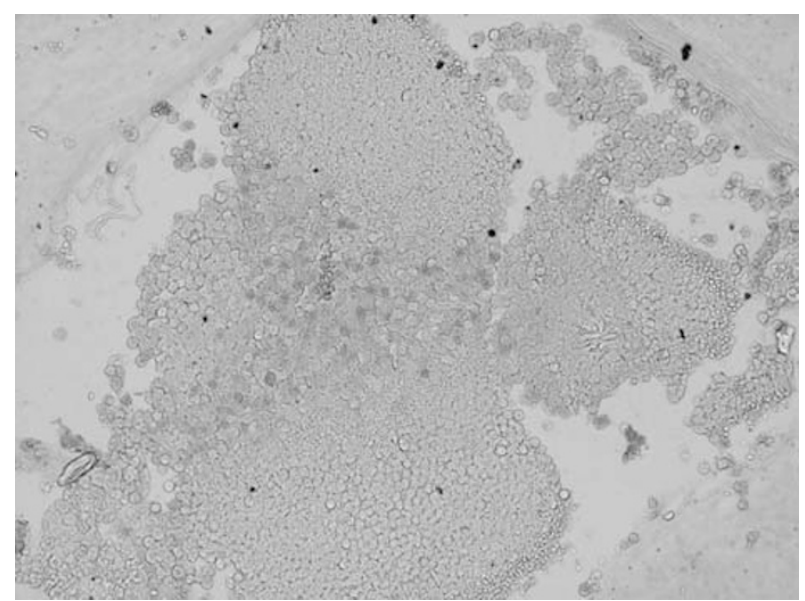

Figure 4 Representative immunohistochemical staining for Chx10. In one sample out of five, Chx10 expression was detected in some of the retinoblastoma tumour cells. Original magnification $\times 400$.
Next, as neuronal and glial cell markers, GFAP, and MAP2 were tested. The results demonstrated that the expression of GFAP was detected only in the stromal cells of the tumour, presumably representing reactive stromal astrocytes (Figure 5). In contrast, in all the samples, MAP2 was expressed in most of the retinoblastoma cells (Figure 6).

The results of the current study are summarized in Table 1 .

\section{Discussion}

Retinal stem cells expand through cell division, exit cell cycle, commit to a particular cell fate, and execute a differentiation for a particular cell type. If retinal stem cells are the origin of retinoblastomas, the tumour must

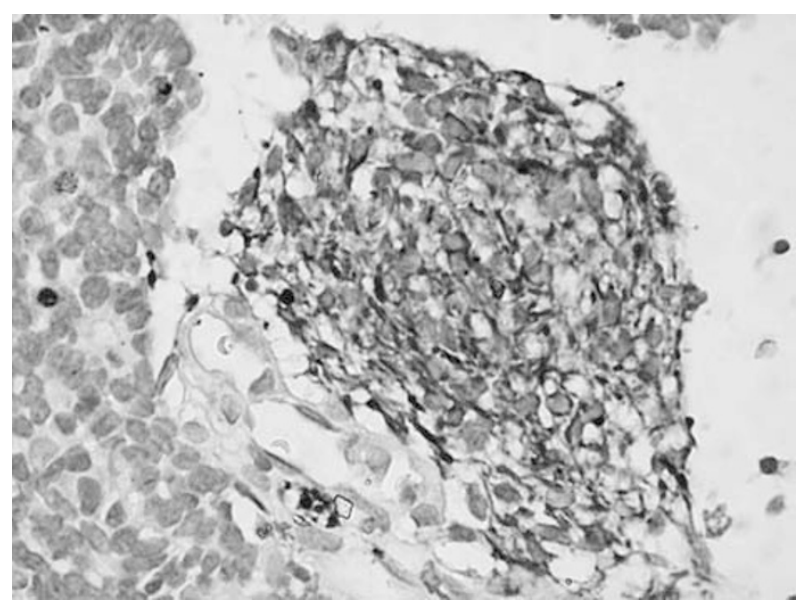

Figure 5 Representative immunohistochemical staining for GFAP. GFAP expression was detected only in the stromal cells of retinoblastomas. Original magnification $\times 400$.

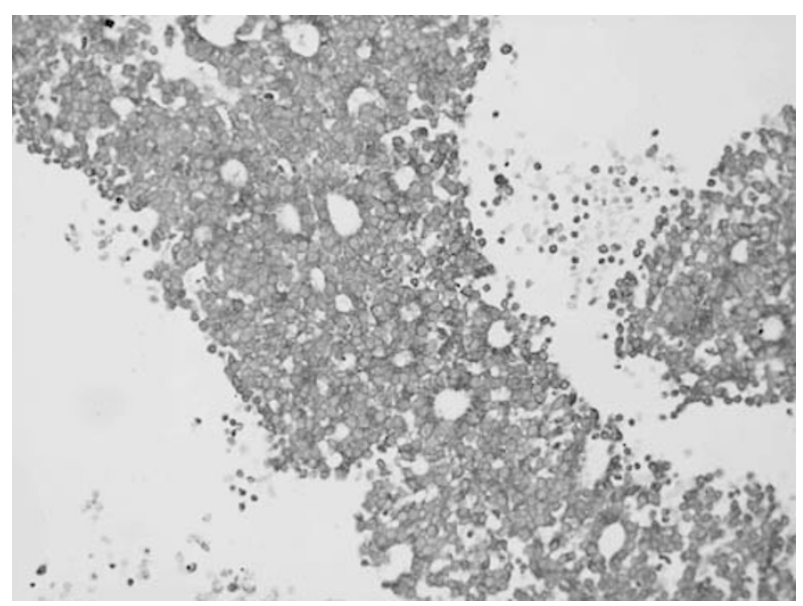

Figure 6 Representative immunohistochemical staining for MAP2. In all samples, MAP2 was expressed in most of the retinoblastoma cells. Original magnification $\times 400$. 
express a range of retinal stem cell markers as well as differentiation markers. Several immunohistochemical analyses support that several types of cell markers are detected in the retinoblastoma cells. ${ }^{8-10}$ This study differs from the previous studies ${ }^{8-10}$ in which the

immunohistochemical analysis of the retinoblastoma was performed with recently identified cell markers that are expressed in a very specific manner along the course of retinal differentiation. The current study demonstrated little expression of immature retinal cell markers, such as Nestin, Chx10, and HES-1, in the tumour stroma. Expressions of Nestin and GFAP were detected in the interstitial cells that presumably represent reactive Müller cells similar to a previous study, ${ }^{29}$ but not in the tumour stromal cells that constitute the tumour. The tumour stroma was positively immunostained only with a mature neuronal cell marker, MAP-2. Thus, the current findings did not support the stem cell origin model of retinoblastomas.

On the other hand, the current results support the idea that retinoblastomas derive from postmitotic cells. In particular, the current study supports that among postmitotic cells, the origin cells are neuronal cells but not glial cells. This is in good accordance with some previous studies. For example, Sun et $a l^{2}$ immunostained the tumour with antibodies against GFAP, Leu-7, NSE, and Opsin, and demonstrated that NSE and Opsin are expressed in the tumour, concluding that the tumour might differentiate especially into the visual cell. Kivela et al assumed the neuronal cells as the origin of the tumour because most of the cells within the tumour were immunostained with NSE. ${ }^{3,4}$ Another immunohistochemical study demonstrated that tumour cells forming rosettes showed positive immunostaining with synaptophysin and NSE and negative immunostaining with GFAP and S-100 antigen. ${ }^{6}$ Moreover, retinoblastomas consist of cells expressing differentiated neuronal phenotypes during cultivation in vitro. ${ }^{5}$ Thus, it is rational to assume that the tumour has arisen from committed neuronal cells in our samples.

There are several limitations in our study. First, it should be noted that the tumours investigated might not reflect the origin of the cells that have built the tumour. Normal adult retina does not contain stem cells in the neuroretina but cell culture disclosed that there are retinal stem cells at the ciliary margin. ${ }^{23}$ Thus, only cell culture may determine the origin of the tumour. Therefore, it may be immature to conclude that the tumour stroma was positively immunostained only with a mature neuronal cell marker, MAP-2, so that retinoblastoma cell does not come from the stem cells. Second, because many cases were differentiation types in this study, there may not have been the nestin expression. Alternatively, it is possible that differentiation of the cells continued to some extent, even after the cells are immortalized. It is an important issue for future research whether the expression of markers is different in mature tumours $v s$ nascent tumours arising from the inner nuclear layer. ${ }^{30}$ Considering the heterogeneity of retinoblastomas, the current results do not exclude the possibility that some retinoblastomas could result from cancer stem cells. Further studies that include a larger number of samples, together with enhanced knowledge of yet unknown retinal cell markers, could provide us with insight into the pathogenesis of retinoblastomas.

\section{References}

1 Dyer MA, Bremner R. The search for the retinoblastoma cell of origin. Nat Rev Cancer 2005; 5: 91-101.

2 Sun XL, Yokoyama T, Minoda K, A S. Immunohistochemical studies of retinoblastoma. Jpn J Ophthalmol 1990; 34: 149-157.

3 Kivela T. Neuron-specific enolase in retinoblastoma. An immunohistochemical study. Acta Ophthalmol (Copenhagen) 1986; 64: 19-25.

4 Kivela T, Tarkkanen A, Virtanen I. Synaptophysin in the human retina and retinoblastoma. An Immunohistochemical and Western Blotting Study. Invest Ophthalmol Vis Sci 1989; 30: 212-219.

5 Griegel S, Heise K, Kindler-Rohrborn A, Rajewsky MF. In vitro differentiation of human retinoblastoma cells into neuronal phenotypes. Differentiation 1990; 45: 250-257.

6 He W, Hashimoto H, Tsuneyoshi M, Enjoji M, Inomata H. A reassessment of histologic classification and an immunohistochemical study of 88 retinoblastomas. A Special Reference to the Advent of Bipolar-Like Cells. Cancer 1992; 70: 2901-2908.

7 Chen D, Livne-bar I, Vanderluit JL, Slack RS, Agochiya M, Bremner R. Cell-specific effects of RB or RB/p107 loss on retinal development implicate an intrinsically death-resistant cell-of-origin in retinoblastoma. Cancer Cell 2004; 5: 539-551.

8 Kyritsis AP, Tsokos M, Triche TJ, Chader GJ. Retinoblastoma - origin from a primitive neuroectodermal cell? Nature 1984; 307: 471-473.

9 Shuangshoti S, Chaiwun B, Kasantikul V. A study of 39 retinoblastomas with particular reference to morphology, cellular differentiation and tumour origin. Histopathology 1989; 15: 113-124.

10 Ohira A, Yamamoto M, Honda O, Ohnishi Y, Inomata $\mathrm{H}$, Honda Y. Glial-, neuronal - and photoreceptor-specific cell markers in rosettes of retinoblastoma and retinal dysplasia. Curr Eye Res 1994; 13: 799-804.

11 Taylor HR, Carroll N, Jack I, Crock GW. A scanning electron microscopic examination of retinoblastoma in tissue culture. Br J Ophthalmol 1979; 63: 551-559.

12 Mohan A, Kandalam M, Ramkumar HL, Gopal L, Krishnakumar S. Stem cell markers: ABCG2 and MCM2 expression in retinoblastoma. $\mathrm{Br} J$ Ophthalmol 2006; 90: 889-893.

13 Mirshahi M, Boucheix C, Dhermy P, Haye C, Faure JP. Expression of the photoreceptor-specific S-antigen in human retinoblastoma. Cancer 1986; 57: 1497-1500.

14 Perentes E, Herbort CP, Rubinstein LJ, Herman MM, Uffer S, Donoso LA et al. Immunohistochemical 
characterization of human retinoblastomas in situ with multiple markers. Am J Ophthalmol 1987; 103: 647-658.

15 Munier FL, Balmer A, van Melle G, Gailloud C. Radial asymmetry in the topography of retinoblastoma. Clues to the Cell of Origin. Ophthalmic Genet 1994; 15: 101-106.

16 Nork TM, Schwartz TL, Doshi HM, Millecchia LL. Retinoblastoma. Cell of Origin. Arch Ophthalmol 1995; 113: 791-802.

17 Reya T, Morrison SJ, Clarke MF, Weissman IL. Stem cells, cancer, and cancer stem cells. Nature 2001; 414: 105-111.

18 Lendahl U, Zimmerman LB, McKay RD. CNS stem cells express a new class of intermediate filament protein. Cell 1990; 60: 585-595.

19 Almqvist PM, Mah R, Lendahl U, Jacobsson B, Hendson G. Immunohistochemical detection of nestin in pediatric brain tumors. J Histochem Cytochem 2002; 50: 147-158.

20 Hemmati HD, Nakano I, Lazareff JA, Masterman-Smith M, Geschwind DH, Bronner-Fraser $\mathrm{M}$ et al. Cancerous stem cells can arise from pediatric brain tumors. Proc Natl Acad Sci USA 2003; 100: 15178-15183.

21 Singh SK, Hawkins C, Clarke ID, Squire JA, Bayani J, Hide T et al. Identification of human brain tumour initiating cells. Nature 2004; 432: 396-401.

22 Cepko CL, Austin CP, Yang X, Alexiades M, Ezzeddine D. Cell fate determination in the vertebrate retina. Proc Natl Acad Sci USA 1996; 93: 589-595.

23 Tropepe V, Coles BL, Chiasson BJ, Horsford DJ, Elia AJ, McInnes RR et al. Retinal stem cells in the adult mammalian eye. Science 2000; 287: 2032-2036.
24 Burmeister M, Novak J, Liang MY, Basu S, Ploder L, Hawes NL et al. Ocular retardation mouse caused by $\mathrm{Ch} \times 10$ homeobox null allele: impaired retinal progenitor proliferation and bipolar cell differentiation. Nat Genet 1996; 12: 376-384.

25 Liu IS, Chen JD, Ploder L, Vidgen D, van der Kooy D, Kalnins VI et al. Developmental expression of a novel murine homeobox gene (Chx10): evidence for roles in determination of the neuroretina and inner nuclear layer. Neuron 1994; 13: 377-393.

26 Kageyama R, Sasai Y, Akazawa C, Ishibashi M, Takebayashi K, Shimizu C et al. Regulation of mammalian neural development by helix-loop-helix transcription factors. Crit Rev Neurobiol 1995; 9: 177-188.

27 Tomita K, Ishibashi M, Nakahara K, Ang SL, Nakanishi S, Guillemot F et al. Mammalian hairy and enhancer of split homolog 1 regulates differentiation of retinal neurons and is essential for eye morphogenesis. Neuron 1996; 16: 723-734.

28 Kobayashi M, Takezawa S, Hara K, Yu RT, Umesono Y, Agata $\mathrm{K}$ et al. Identification of a photoreceptor cell-specific nuclear receptor. Proc Natl Acad Sci USA 1999; 96: 4814-4819.

29 Kohno H, Sakai T, Kitahara K. Induction of nestin, Ki-67, and cyclin D1 expressionin Müller cells after laser injury in adult rat retina. Graefes Arch Clin Exp Ophthalmol 2006; 244: 90-95.

30 Gallie BL, Campbell C, Devlin H, Duckett A, Squire JA. Developmental basis of retinal-specific induction of cancer by RB mutation. Cancer Res 1999; 59: 1731s-1735s. 